
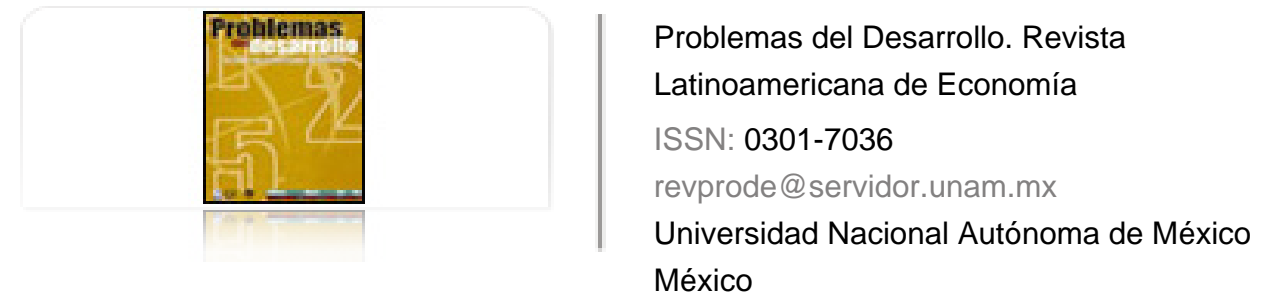

Trujillo Félix, Juan de Dios; Schwentesius Rindermann, Rita; Gómez Cruz, Manuel Ángel; Maya Ambía, Carlos

Las reformas de las políticas agrícolas de Estados Unidos, la Unión Europea y México. Deficiencias de la metodología de la OCDE para su medición

Problemas del Desarrollo. Revista Latinoamericana de Economía, vol. 36, núm. 142, julio-septiembre, 2005, pp. 51-73

Universidad Nacional Autónoma de México

Distrito Federal, México 


\section{LAS REFORMAS DE LAS POLÍTICAS AGRÍCOLAS de Estados Unidos, la Unión EuRopea y MÉXICO. DEFICIENCIAS DE LA METODOLOGíA DE LA OCDE PARA SU MEDICIÓN Juan de Dios Trujillo Félix
Rita Schwentesius Rindermann"**
Manuel Ángel Gómez Cruz
Carlos Maya Ambía****}

Fecha de recepción: 10 de abril de 2005. Fecha de aceptación: 10 de agosto de 2005.

\section{Resumen}

Los cambios de política agrícola de Estados Unidos y la Unión Europea son un punto de referencia para México: la disputa entre ambos ha sido importante para entender la naturaleza de las disciplinas de la Organización Mundial de Comercio (OMC). Este trabajo muestra que los avances en las reformas están por debajo de las expectativas, según la base de datos de la Organización para la Cooperación y Desarrollo Económicos (OCDE) y su metodología. Sin embargo, hubo un cambio hacia politicas menos conectadas; es decir, las medidas de sostén de precios de mercado se están volviendo menos importantes, aunque todavía son significativas. Se ilustra, además, acerca de los defectos de la metodología de la OCDE, con base en la categoría PSE (price support estimate) y el caso mexicano.

Palabras clave: comparativo, reformas, políticas, agrícolas, PSE, México.

* Profesor investigador del Instituto de Investigaciones Económicas y Sociales de la Universidad Autónoma de Sinaloa (UAS). Correo electrónico: trujillo@uas.uasnet.mx

* Directora del Centro de Investigaciones Económicas, Sociales y Tecnológicas de la Agroindustria y la Agricultura Mundial (CIESTAAM) de la Universidad Autónoma Chapingo. Correo electrónico: rsr@avantel.net

*** Catedrático del ciestaAm de la Universidad Autónoma Chapingo. Correo electrónico: ciestaam@avantel.net

**** Catedrático del doctorado en Ciencias Sociales de la Universidad Autónoma de Sinaloa (UAS). Correo electrónico: maya@uas.uasnet.mx 


\section{JUAN DE DIOS TRUJILLO FÉLIX, RITA SCHWENTESIUS RINDERMANNY OTROS}

\section{Abstract}

Changes in u.s. and European Union farm policy are a reference point for Mexico: the dispute between them has been important for understanding the nature of the disciplines of the World Trade Organization (WTO). The present study shows that the advances in reforms are not coming up to expectations, according to the Organization for Economic Cooperation and Development (OECDE) data base and its methodology. However, there was a change towards less connected policies, the measures for sustaining market prices are becoming less important, although they are still significant. This also illustrations the defects in the OECD's methodology , based on the Price Support Estimate (PSE) category and the Mexican case.

Keywords: comparative, reforms, policies, farm, PSE, Mexico.

\section{Résumé}

Les changements de la politique agricole des usa et de l'Union Européenne sont un point de référence pour le Mexique: la dispute entre les deux est importante pour comprendre la nature des disciplines de l'Organisation Mondiale du Commerce (омC). Ce travail montre que les progrès dans les réformes sont en dessous des attentes, selon la base de données de l'Organisation pour la Coopération et le Développement Economiques (OCDE) et sa méthodologie. Cependant, il y a eu un changement vers des politiques moins connectées; c'est à dire, les mesures de soutien des prix du marché deviennent moins importantes, même si elles sont encore significatives. On donne des exemples, en plus, sur les défauts de la méthodologie de l'OCDE, sur la base de la catégorie PSE (Price Support Estimate) et du cas mexicain.

Mots clés: comparatif, réformes, politiques, agricoles, PSE, Mexique.

\section{Resumo}

As mudanças de politica agrícola dos Estados Unidos e da União Europeia são um ponto de referência para o México a disputa entre os dois tem sido importante para entender a natureza das disciplinas da Organização Mundial de Comércio (OMC). Este trabalho mostra que os abanicos nas reformações estão por debaixo das expectativas, segundo a base de dados da Organização para a Cooperação e Desenvolvimento Económicos (OCDE) e a sua metodología. Todavía, houve uma mudança a respeito das políticas menos conectadas, aliás, as medidas de suporte de preços de mercado estão se tornando menos importantes, contudo ainda são significativas. Exemplifica-se, além do mais, acerca dos defeitos da metodología da oCDE, baseada na categoría PSE (Price Support Estimate) e o caso mexicano.

Palavras chave: comparativo, reformções, politicas, agrícolas, PSE, México.

\section{Dêsarrrollo}




\section{Introducción}

$\mathrm{D}$

urante los años noventa, los cambios en las políticas agrícolas de Estados Unidos y la Unión Europea constituyeron un marco de referencia importante para México, porque ellos establecieron, hasta cierto punto, los márgenes y visiones desde los cuales podía moverse el diseño. Esto fue así porque la naturaleza de los debates en torno a la agricultura en la Ronda de Uruguay fue determinada por la confrontación entre ambas potencias.

En otro sentido, los esquemas de política de Estados Unidos y la Unión Europea también han sido referentes básicos para México en años recientes. En el primer caso, porque la eventualidad de la suscripción del Tratado de Libre Comercio de América del Norte hizo que los diseñadores de política en México vieran más explícitamente a la agricultura estadounidense como modelo por imitar, tratando de que en México se diera lo más rápidamente posible el tipo de transformaciones en la estructura productiva que se había dado en aquel país a lo largo del tiempo; en tal sentido, se presumía de que la adopción de los enfoques de mercado críticos de las políticas agrícolas, aun de las de Estados Unidos, podían elevar la competitividad de la agricultura mexicana y amortiguar los daños del acuerdo comercial.

Además, los cambios de política en ese país han sido un referente básico para México porque una mejor información ha llevado a que los productores organizados presionen y propongan modificaciones para compensar beneficios o el efecto de las medidas de Estados Unidos. México ya no puede darse el lujo de ignorar dichos cambios en el país vecino.

Por otra parte, la Unión Europea ha sido un referente porque ha funcionado como un factor de resistencia frente a enfoques puramente centrados en el mercado, en la medida en que ha puesto atención en los denominados aspectos no comerciales —en el léxico de las negociaciones multilaterales-. Es decir, en la Unión Europea se ha mantenido la idea de la defensa de la excepcionalidad de la agricultura, al reivindicar su papel en la producción de bienes públicos y semipúblicos, mediante el concepto de multifuncionalidad, ${ }^{1}$ en tanto que ha dado respuesta a nuevas preferencias sociales - la sustentabilidad en el manejo de los recursos - y de los consumidores, a fin de elevar el grado de consenso en torno a la política agrícola común (PAC) de la región. Aunque Estados Unidos fue pionero en la implantación de programas de conservación, dentro de un esquema de política agrícola, el enfoque de la Unión Europea ha ido mucho más lejos: los debates en torno a los cambios

Sobre este término, véase Massot (2002), las publicaciones de la OCDE (2001b, 2003) y Paarlberg et al. (2002).

\section{Desaarrollo}


en las políticas de esta última han sido fuente de inspiración para aquellos interesados en la continuidad de los pequeños productores, además de los aspectos ambientales y de manejo de los recursos.

En cuanto a la reforma en Estados Unidos, cabe señalar que a lo largo de sucesivas legislaciones, había estado desplazándose hacia instrumentos de mayor orientación al mercado, para que no fueran las señales de la política las que determinaran las decisiones de los productores. La expresión más acabada de esa trayectoria fue la legislación correspondiente a 1996. Con ella se dio libertad a los productores de sembrar cualquier cultivo en cualquier extensión de tierra, exceptuando hortalizas y frutas, en tanto eran desaparecidos los precios objetivo, los pagos de deficiencia y los esquemas de retiro obligatorio estacional de tierras; además, como compensación, se les concedieron pagos directos por contratos de flexibilidad en la producción. No obstante, en 2002 fueron reintroducidos los precios objetivo para el cálculo de pagos contracíclicos, mientras se conservaba el esquema de pagos directos. Con esta última reforma se pretendió crear una red de seguridad para el productor, recuperando el sentido anticíclico a la evolución de los precios de los viejos instrumentos de política. ${ }^{2}$

Por su parte, la PAC de la Unión Europea, fundada en 1958, no había experimentado cambios mayores hasta 1992. Con su reforma, se abrió la posibilidad de concluir la Ronda de Uruguay, mediante el desplazamiento hacia pagos por hectárea o cabeza animal, y la definición de una trayectoria hacia la reducción o desaparición de precios de intervención, así como hacia la modificación del régimen comercial de impuestos variables a las importaciones y subsidios a las exportaciones. Los acuerdos de la Agenda 2000 persistieron en la misma senda, en tanto que su revisión de medio término (en 2003) definió una perspectiva de desplazamiento hacia pagos directos completamente desconectados. ${ }^{3}$

La exposición anterior explica por qué se ha tenido interés en los casos arriba mencionados. En este trabajo se hace un análisis comparativo de la evolución agregada de los cambios de política agrícola en Estados Unidos, la Unión Europea y México, usando la base de datos y la metodología de la Organización para la Cooperación y Desarrollo Económicos (OCDE) ${ }^{4}$ las cuales han desempeñado un papel de primer orden en la promoción y exigencia de reforma de dichas políticas y en las negociaciones multilaterales sobre comercio agrícola. Se ha pretendido verificar si efectivamente esas políticas se han vuelto

2 Los cambios en los esquemas de política de Estados Unidos pueden encontrarse con mayor detalle en Ingersent y Rayner (1999), Knutson et al. (1998), Normile y Leetmaa (2004), Orden et al. (1999), Piccinini y Loseby (2001) y Ray et al. (2003), entre otros autores.

3 Existe una bibliografía amplia acerca de los cambios hechos a la PAC; puede consultarse a Folmer et al. (1995), Gardner (1996), Grant (1997), Ingersent y Rayner (1999), Izam y Onffroy (2000), Massot (2002) y Normile y Leetmaa (2004).

4 OECD (por sus siglas en inglés), Producer and Consumer Support Estimates, OECD Database 1986 2003, http://www.oecd.org/dataoecd/33/50/32361372.ZIP. 
más uniformes, más orientadas al mercado y menos basadas en la intervención de los gobiernos, según el propósito global de impulso a las reformas. De acuerdo con el comportamiento observado, los avances están lejos de ser los esperados, pero se precisa que ha habido un desplazamiento desde las medidas de sostén de precios hacia otras que implican transferencias gubernamentales directas. Además, dada su aceptación generalizada, se llama la atención en torno a los problemas que presenta esta metodología, los cuales conducen a errores de estimación.

Los autores buscan mostrar cómo su manejo usual conduce a resultados significativamente sesgados. Para ello se ha recurrido al análisis de la estimación del apoyo al productor (producer support estimate, PSE), ${ }^{5}$ y al caso de México. Tanto la información como la metodología de la OCDE indican que este país ha retrocedido en la orientación de mercado de sus políticas, lo cual es inconsistente con la evidencia de la profundidad de las medidas tomadas en esa dirección desde los años ochenta. Por otra parte, cabe señalar que este trabajo no hace una corrección de las estimaciones ni tampoco conduce a la elaboración de una metodología alternativa. Dichas tareas serán abordadas en un futuro ensayo.

\section{La metodología de la OCDE}

Debido al mandato de sus estados miembros, derivado de negociaciones para fomentar un comercio más libre de productos agrícolas, la OCDE ha sido un actor importante en el análisis y monitoreo sistemático de las reformas, para lo cual ha construido, incluso, un sistema de indicadores propio. Su base de datos, por otra parte, tiene la ventaja de la oportunidad, en comparación con la información que los gobiernos reportan a la Organización Mundial del Comercio (omc), y comprende de 1986 hasta 2003. Para el caso de México, el periodo es bastante pertinente, porque inició su proceso de reforma con la entrada al General Agreement on Tariffs and Trade (GATT) en 1986, aunque su profundización ocurrió a partir de 1989, durante la administración del presidente Carlos Salinas de Gortari. México fue aceptado como miembro de la OCDE en 1994.

Conforme a la metodología de la OCDE, el análisis de las políticas y su seguimiento comparativo se efectúa mediante ocho categorías o indicadores principales: $a$ ) la estimación del apoyo total (total support estimate, TSE), b) la estimación del apoyo al productor (PSE), c) la estimación de los apoyos en servicios generales proporcionados a la agricultura (general services support estimate, GSSE), d) el coeficiente de protección nominal al productor (producer nominal protecction coefficient, NPCP), e) el coeficiente de asistencia nominal al productor (producer nominal assistance coefficient, $\mathrm{NACP}$ ), $f$ ) la estimación del apoyo al consumidor (consumer support estimate, CSE), g) el coeficiente de protección

5 A lo largo del trabajo se ha optado por utilizar las siglas en inglés, terminología que es usada con mayor frecuencia.

\section{Desaarrollo}


nominal al consumidor (consumer nominal protecction coefficient, NPCC), y $h$ ) el coeficiente de asistencia nominal al consumidor (consumer nominal assistance coefficient, NACC). Además, tanto de la PSE, como de la CSE y la TSE se derivan otros tres indicadores específicos expresados en términos porcentuales: los \%PSE, \%CSE y \% TSE.

Los conceptos arriba enunciados se refieren, en realidad, a las tres partes que se ven involucradas en las políticas, ya sea como beneficiarios o perjudicados: consumidores, productores y contribuyentes. Desde una visión de estática comparativa ellos expresan que las acciones de gobierno sólo provocan transferencias de una fuente hacia otras y no propiamente el aumento del ingreso global de la sociedad. Con las reformas se ha buscado la disminución de la carga que representan para consumidores y contribuyentes las políticas en apoyo a la agricultura. El consumidor aparece como el mayor beneficiario de las reformas, por medio de precios bajos y mayor disponibilidad de bienes.

Implícitamente, la metodología de la OCDE no concede efectos virtuosos a la intervención pública en la agricultura, pues se centra en sus efectos negativos: desequilibrios prevalecientes en los mercados agrícolas mundiales, debido a políticas que impiden la transmisión de las señales de mercado, haciendo que la oferta prevalezca sobre la demanda efectiva y haya persistencia de precios a la baja; alto costo presupuestal de las políticas, hasta constituir una gran carga para la economía en su conjunto, y distorsión de la competencia en el comercio internacional, lo cual actúa en contra del principio de ventaja comparativa, con efectos dañinos para muchos países en desarrollo (OCDE, 2000:138).

Debido al seguimiento sistemático y oportuno de las políticas de los países miembros y la publicación periódica de su monitoreo, el uso de los indicadores de la OCDE se ha popularizado. Al mismo tiempo, sus defectos se han vuelto cada vez más visibles, aunque tienden a pasarse por alto, a falta de datos más oportunos y mejores. Por definición, fueron diseñados para estimar las transferencias, pero no son buenos indicadores del grado de distorsión en el comercio. Con base en Wise (2004) y Haniotis y Bascou (2003), a continuación se resumen las críticas más frecuentes.

En principio, la estimación de las transferencias hacia los productores se realiza extrapolando, a partir de una lista de productos. Como los productos excluidos son los menos afectados por políticas que abren una brecha entre el precio interno y el externo, ello conduce a una sobreestimación del apoyo concedido a los productores. En el periodo 2001-2003, la lista representó 65.2\% del valor total de la producción agrícola en Estados Unidos, $70.5 \%$ en la Unión Europea y $67 \%$ en México. ${ }^{6}$ A mayor porcentaje de productos incluidos, mayor confiabilidad en los cálculos.

La PSE se integra, de manera agregada, con los que se calculan a partir de la diferencia entre los precios domésticos y los internacionales — concepto denominado market price

${ }_{6}$ Cálculos propios con base en datos de OCDE (2004) y FAO, FAOSTAT (2004).

\section{Desarrrollo}


support, MPS - y un conjunto de distintas categorías de pagos no relacionados con el sostén de precios, las cuales implican propiamente subvenciones de los gobiernos a favor de los productores. Para calcular el sostén de precios de mercado (MPS) se toma como referencia un precio mundial, el cual puede no ser el adecuado si expresa el efecto depresivo de las políticas domésticas del país exportador sobre los precios. La medición es muy sensible a cuál sea el precio de referencia, y en ello radica la segunda crítica relevante que suele hacerse a la estimación de la OCDE: es difícil determinar cuál es el precio mundial correcto. Esta institución suele elegir el más competitivo, aquél más bajo entre los distintos países exportadores, pero ello tiende a elevar sistemáticamente la valoración, pues tal precio puede no reflejar necesariamente el representativo mundial. Un indicador así no puede ser válido para medir la magnitud de la distorsión causada por las políticas y da estimaciones incorrectas del grado de apoyo con medidas de sostén de precios.

Las políticas públicas en países exportadores pueden llevar a inducir precios muy bajos, lo cual hace que el producto importado parezca más competitivo, pero ello puede ser resultado de un dumping, es decir, de vender a precios por debajo de los costos. Esto es particularmente importante en el caso de México, pues el precio que importa es del de Estados Unidos. Según el análisis de IATP (2004), Estados Unidos ha vendido sistemáticamente a precios de dumping en productos como trigo, soya, maíz, algodón y arroz. Por tanto, por este medio ha habido una sobreestimación del apoyo al productor. Además, una variación producto de una baja en el precio externo hace ver como si un país estuviera adoptando políticas más agresivas de sostén de precios, cuando bien pudo no haber ocurrido cambio alguno; por el contrario, el apoyo pudo, incluso, haber descendido. Es decir, se interpreta como una transferencia mayor hacia los productores algo que no se deriva de un cambio en la política comercial o en las políticas de orden interno.

Junto al dumping hay otro problema adicional. Las estimaciones suponen mercados en los cuales prevalece la competencia perfecta (países pequeños sin poder para afectar los precios). Sin embargo, en la práctica, un número limitado de naciones controla la mayor parte del mercado de cierto producto y alguno de ellos ejerce un liderazgo en la formación del precio. Además, son pocas las grandes comercializadoras que controlan el mercado. Lo anterior tiene una implicación importante: la diferencia entre el precio doméstico y el internacional puede estar siendo capturada en parte, por intermediarios o procesadores. Por consiguiente, el productor puede no ser el beneficiario absoluto de lo estimado como apoyo dirigido a él. Por otra parte, el consumidor puede no estar recibiendo realmente la baja de precio al productor.

Un defecto más de la metodología de la OCDE se refiere a los tipos de cambio, los cuales tienden a subvaluar el poder de compra en países de más bajo ingreso, debido a que servicios no caros no son comerciados internacionalmente. La fuente de error puede ser doble, ya sea al convertir el precio internacional a doméstico, o bien al trasladar las estima-

\section{Desaarrollo}


ciones en moneda nacional a dólares, para hacer comparaciones internacionales. ${ }^{7}$ Todavía más, en numerosas economías en desarrollo, los procesos de reforma económica han conducido a procesos de sobrevaluación, interrumpidos por crisis cambiarias. En condiciones de sobrevaluación o subvaluación, difícilmente las estimaciones pueden ser correctas, porque los precios son defectuosos. Esto es particularmente cierto en el caso de México, según se verá en el trabajo, pues en este país el tipo de cambio ha sido usado sistemáticamente para disciplinar precios. Como la sobrevaluación favorece a los consumidores y perjudica la competitividad de los productores, ello ha implicado que los precios externos aparezcan artificialmente bajos. En este contexto, el nivel de transferencias de los consumidores a los contribuyentes parece ser más elevado de lo que en realidad es. Por tanto, las estimaciones de la PSE y la TSE están dando lugar al registro de valores distorsionados.

A pesar de las deficiencias señaladas, la base de datos de la ocDE es útil para conocer las tendencias de las políticas agrícolas, en lo particular de Estados Unidos y de la Unión Europea, y permite cumplir con el objetivo de este texto, que es analizar los cambios y la trayectoria en las políticas. El mayor problema se presenta en el caso de México, donde las deficiencias de la metodología llevan a una constante sobreestimación de los apoyos. Es por ello que se destaca este aspecto.

\section{La estimación del apoyo a los productores y la trayectoria de las reformas}

Las transferencias percibidas por los productores son cuantificadas mediante la PSE, cuya definición es el valor monetario anual de las transferencias brutas de los consumidores y contribuyentes en apoyo a los productores agrícolas, calculadas a precios del productor (a puerta de predio), derivadas de medidas de política que apoyan la agricultura. Con ese concepto, la OCDE da una estimación de las transferencias generadas por las políticas respecto de una situación en la cual tales políticas están ausentes. En esa circunstancia, los productores agrícolas únicamente serían objeto de políticas generales (impositivas, ambientales, económicas y sociales), de manera que no tendrían ningún estatus especial en relación con otros productores o empresas en las demás áreas de actividad económica.

Según la base de datos de la OCDE, los montos de apoyo total en beneficio de los productores, medidos por la PSE, históricamente han sido superiores en la Unión Europea (véase Gráfica 1). En los últimos tres años de la serie disponible, la ayuda a los productores en Estados Unidos representó 43.5\% de los montos proporcionados a los productores de dicha región. En ese mismo año, los apoyos canalizados por México a sus productores

7 Un procedimiento alternativo propuesto es el uso de paridades de poder de compra, ya que éstas pueden ser una medida más precisa del costo de oportunidad de los recursos (véase Wise, 2004). 


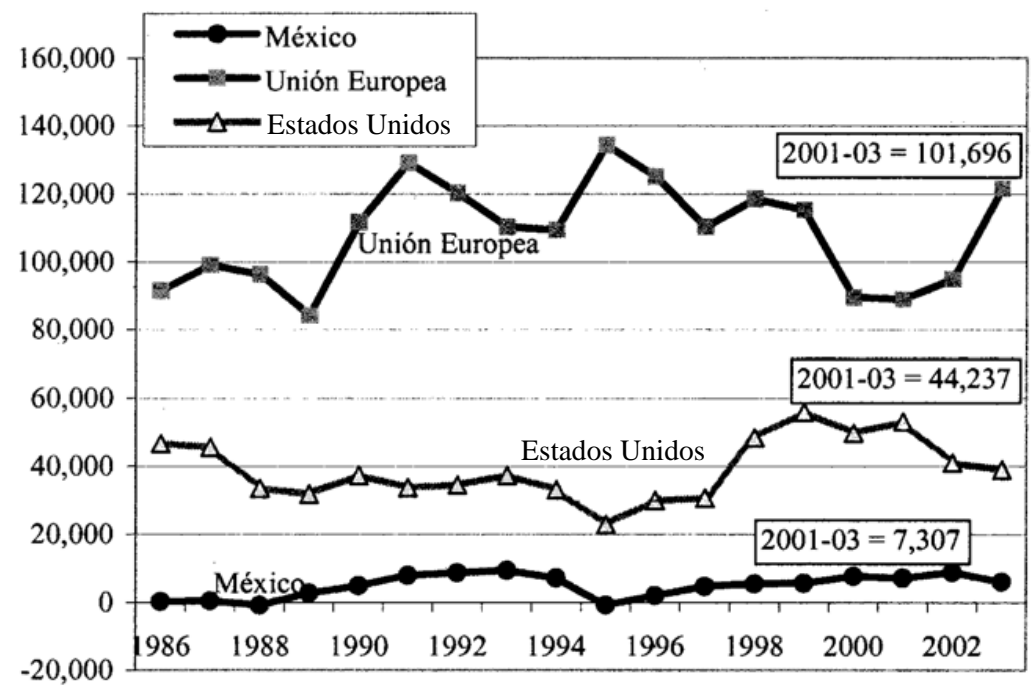

Gráfica 1. Evolución comparativa de la estimación del apoyo al productor (PSE) en México, Estados Undios y la Unión Europea, 1986-2003 (millones de dólares).

Fuente: http://oecd.org/document/58/0,2340,en_2649_33773_32264698_1_1_1_1,00.html

equivalieron a $7.2 \%$ de los asignados por la Unión Europea y a $16.5 \%$ de los de Estados Unidos. En una primera aproximación, en términos relativos, las transferencias hacia los productores agrícolas en México pueden considerarse comparativamente altas, tomando en cuenta la dimensión relativa de la economía. Sin embargo, este razonamiento es engañoso, según se verá más adelante.

En general, después de haber observado un patrón ascendente hasta 1991, los apoyos proporcionados a los productores en la Unión Europea habían venido descendiendo, hasta experimentar un repunte recientemente. El monto de la PSE de la Unión Europea fue de 95610 millones de dólares, en promedio, para el periodo 1986-1988, años base para la negociación del GATT, y ascendió a 101696 millones de dólares en 2001-2003, después de haber alcanzado un monto de 120312 en 1990-1991. Así pues, en el largo plazo, ocurrió un descenso de los apoyos respecto de 1990-1991, pero no con relación al periodo cuando fue lanzado el Acuerdo de la Ronda de Uruguay. En tal sentido, en la perspectiva de la reforma, los resultados han quedado muy por debajo de lo esperado.

En contraste, en Estados Unidos los apoyos siguieron, en general, una inclinación descendente hasta 1995, para iniciar desde ese año una tendencia ascendente hasta 1999. La caída posterior ha implicado la conservación de montos más altos que los cuantificados para 1995. Este comportamiento muestra el fracaso de la legislación de 1996, ya que en 1999 fueron alcanzados niveles récord. En tal sentido, el enfoque de orientación al mercado propugnado por los reformadores liberales resultó decepcionante. Una mejor perspec- 
tiva de precios en los últimos años hizo posible que no persistiera la inclinación hacia el alza de los apoyos. Sin embargo, este comportamiento de los montos sugiere la existencia de una fuerte vinculación de las medidas de política con la evolución de los precios, aspecto que las reformas de las políticas agrícolas supuestamente pretendían atacar, a fin de permitir un ajuste más rápido a las condiciones de mercado.

En términos relativos, la PSE de Estados Unidos mostró una disminución respecto de la de la Unión Europea hasta 1995, si bien tal situación fue revertida posteriormente. Al grado de que si en 1995 la PSE del primero equivalía a 17.1\% de la PSE de la segunda, ese porcentaje aumentó a un nivel récord de $59.1 \%$ en 2001. En 2003 cayó a 32\%, por el efecto combinado del descenso de la PSE de Estados Unidos y su incremento en la Unión Europea. En el debate en torno a la legislación del primero, los altos niveles de apoyo existentes en la segunda han sido usados con frecuencia como argumento para justificar el incremento de los apoyos domésticos; no obstante, los incrementos derivados de las medidas de emergencia y la legislación de 2002 crearon el espacio que la Unión Europea requería para mantener el gasto a favor de sus productores. Las pautas de comportamiento de las potencias son expresión del proceso de desgaste experimentado por las reformas, habiéndose abierto terreno al escepticismo en relación con el futuro de la Ronda de Doha de la omc y en torno a las perspectivas de las reformas de las políticas agrícolas.

México marca el contraste en lo que se refiere al apoyo dado a los productores. El comportamiento de su PSE ha sido bastante inestable a lo largo del periodo considerado, con valores negativos (transferencias de los productores hacia los consumidores) en algunos años (1986, 1988 y 1995). Entre 1989 y 1993 registró una inclinación al alza en los apoyos que no se sostendría. En 1993 consignó el nivel más alto de la PSE, el cual se deriva del ambiente de inestabilidad de la economía y está estrechamente vinculado a la historia del tipo de cambio. En 2001-2003, la PSE de México representó 7.4\% de la PSE de la Unión Europea y $16.8 \%$ de la de Estados Unidos, porcentajes que reflejan un comportamiento ascendente. Sin embargo, la variabilidad de la PSE ha sido alta, más en relación con Estados Unidos que respecto de la Unión Europea.

\section{Las medidas de sostén de precios de mercado y los cambios en el tipo de politicas}

Para una mayor comprensión de las políticas agrícolas, la PSE es desglosada por la OCDE en ocho subcategorías: $a$ ) sostén de precios de mercado (MPS), ${ }^{8} b$ ) pagos basados en la producción, $c$ ) pagos basados en el área plantada o el número de animales, $d$ ) pagos basados

8 Conforme a la metodología de la OCDE (2001a), este indicador se define como el valor monetario de las transferencias brutas de los consumidores y contribuyentes hacia los productores agrícolas, surgidas de medidas de política que crean una brecha entre los precios en el mercado interno y los precios en frontera de un producto agrícola específico, medido en el nivel de predio. 
en derechos históricos, $e$ ) pagos basados en el uso de insumos, $f$ ) pagos basados en restricciones sobre el uso de insumos, $g$ ) pagos basados en el ingreso agrícola global, y $h$ ) otro tipo de pagos.

En sentido inverso, en este artículo se hace un reagrupamiento de esas subcategorías, a fin de contrastar las medidas de sostén de precios contra el conjunto de pagos, a los cuales aquí denominamos medidas distintas del sostén de precios de mercado. Esta comparación es trascendente porque, en términos del apoyo a los productores, permite reflexionar en torno al grado de desplazamiento desde las medidas que descansan en los consumidores hacia instrumentos que se basan en transferencias de los contribuyentes, aspecto sustancial en el enfoque inicial de reforma de las políticas agrícolas.

\section{Estados Unidos de América (еUA)}

Ambos conjuntos de medidas - las referidas a sostén de precios de mercado (MPS) y las distintas a sostén de precios de mercado (pagos) — observaron un comportamiento descendente en Estados Unidos hasta 1995, pero esta inclinación fue revertida con posterioridad. Históricamente, los montos estimados por la OCDE para ambos grupos no habían sido muy distintos uno del otro, sin embargo, en años recientes se ha abierto una brecha. Por otra parte, después de la legislación de 1996, contra lo que cabría esperar, dado el papel de Estados Unidos en el impulso a cambios de política favorables para la eliminación de distorsiones en los mercados, las medidas agrupadas en la categoría sostén de precios de mercado no disminuyeron en importancia, más bien la incrementaron. De cualquier manera, a partir de 1999 se retorna a la tendencia descendente, dedibo a la normalización en el entorno de precios mundiales.

El regreso a la tendencia descendente en los apoyos a los productores con medidas de sostén de precios de mercado, en compensación, implicó que otras formas de apoyo al productor ganaran significativa relevancia. En 1986-1988, el conjunto de medidas agrupadas en la categoría MPs representaban en promedio $46.7 \%$ del total de apoyos recibidos por los productores, en tanto que en 2001-2003 equivalían a 38\%. En contraste, la estimación de los apoyos distintos al sostén de precios de mercado pasó de 53.3 a $62 \%$.

Los datos de la OCDE respecto de Estados Unidos ciertamente ilustran acerca de la dinámica de la reforma, dado el liderazgo de ese país. Los esfuerzos por mantener un manto protector sobre su agricultura y productores llevaron a que coyunturalmente se instrumentaran medidas que implicaban abrir una brecha entre el precio interno y el externo y, más estructuradamente, a la implantación de programas para transferir recursos públicos. Así pues, el sostén del ingreso de los productores no se ha abandonado, más bien, jugando con las reglas de la омс, ha habido un desplazamiento hacia medidas que implican desembolsos presupuestarios mayores, es decir, que se basan en dinero de los contribuyentes.

La Gráfica 2 ilustra el debilitamiento de la idea de hacer disminuir consistentemente los desembolsos en apoyo a los productores. En un primer momento, por efecto de los

\section{Desaarrollo}




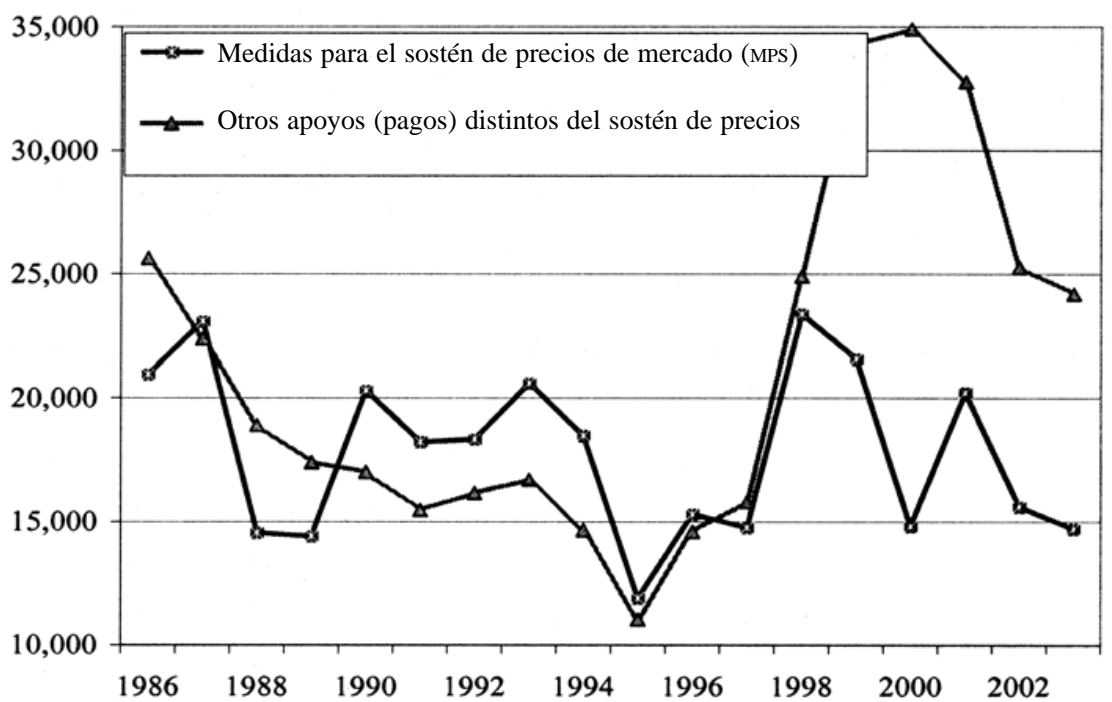

Gráfica 2. Estados Unidos de América. Evolución comparada de las medidas de sostén de precios de mercado (MPS) y el conjunto integrado por otras medidas de apoyo al productor, 1986-2003 (millones de dólares).

Fuente: http://oecd.org/document/58/0,2340,en_2649_33773_32264698_1_1_1_1,00.html

cambios en la legislación agrícola (1996), se adoptó un esquema compensatorio que implicó el desplazamiento hacia transferencias gubernamentales directas; pero, en un segundo momento, esa opción se profundizó, en reacción a escenarios de precios bajos y para no hacer descansar las medidas de política tan marcadamente en los consumidores. De hecho, las medidas clasificadas como distorsionantes tendieron a acercarse a los techos comprometidos con la омc.

En 1996 fueron introducidos los pagos basados en derechos históricos (es decir, los pagos por contratos de flexibilidad en la producción, denominados pagos directos en la legislación de 2002), ${ }^{9}$ pero éstos han caído a partir de 2000. Su monto es importante, aunque al parecer tienden a dejar de ser la principal forma de pago gubernamental, en sentido contrario a lo considerado en el diseño de la reforma de 1996. De acuerdo con la información de la OCDE, históricamente las transferencias basadas en el uso de insumos han jugado un papel de primer orden, pero recientemente esa importancia se elevó, hasta convertirse en la principal forma de pago. Este tipo de apoyos habían sido muy criticados, por inducir una mala asignación de los recursos.

9 Los pagos basados en derechos históricos (payments based on historical entiflements) se refieren a medidas de política que implican transferencias de los gobiernos, en las cuales el cálculo se hizo sobre un referente histórico de apoyo, área, número de animales o producción o grupo de productos específico, sin obligación alguna de continuar plantando o elaborándolos. 


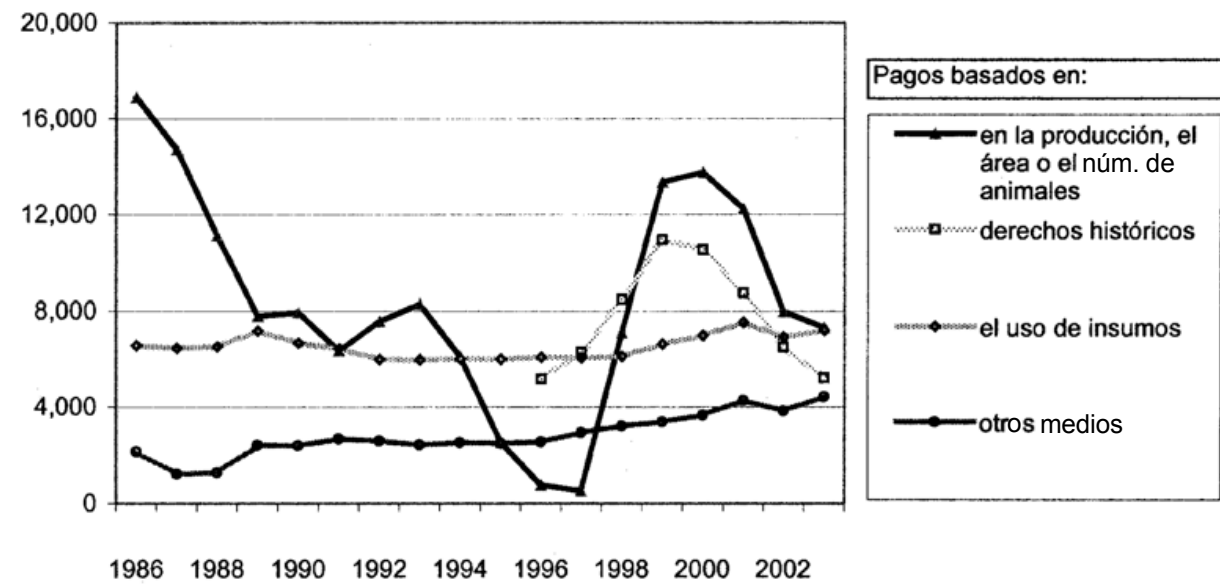

Gráfica 3. Estados Unidos. Evolución e importancia de las distintas categorías consideradas para el cálculo de la estimación del apoyo al productor (PSE), distintas del sostén de precios de mercado (MPS), 19862003 (millones de dólares).

Fuente: http://oecd.org/document/58/0,2340,en_2649_33773_32264698_1_1_1_1,00.html

Los pagos basados en el área o número de animales, clasificados en la caja azul, según el sistema de cajas introducido en la Ronda de Uruguay, también tenían alta importancia, pero en la búsqueda de una mayor orientación al mercado, éstos casi fueron eliminados; sin embargo, experimentaron un repunte a partir de 1998, hasta situarse por sí mismos en la tercera posición en importancia. Si se añaden a esta categoría los pagos basados en la producción, entonces la suma de ambos conceptos resulta similar a la de los insumos en el último año. A pesar de que también habían sido casi desaparecidos, los pagos basados en la producción experimentaron un repunte significativo en la segunda mitad de los años noventa, en respuesta a una situación de baja de precios, al grado de llegar a rivalizar con los pagos basados en derechos históricos. Esto explica por qué en la nueva ronda de negociaciones multilaterales se ha expresado la intención estadounidense de hacer mayor uso de la caja azul. El cambio de posición es, desde luego, inconsistente con el enfoque de la reforma de 1996, la más deliberadamente orientada hacia el mercado. Por otra parte, otras formas de pago registran una inclinación creciente. Aquí se incluyen las relacionadas con el ingreso agrícola global y los pagos que se basan en la restricción al uso de insumos.

Las reformas se hicieron sustancialmente para reducir los esquemas de soporte de precios. Si en estos aspectos se ponía el acento, es bastante obvio que la reforma estadounidense ha dejado mucho que desear al respecto. Lo mismo se puede afirmar en relación con la intención de desplazarse hacia instrumentos desvinculados de las decisiones de producción y de precios. Los apoyos no se redujeron, sino que aumentaron. Además, en la práctica, la 
creatividad estadounidense en el diseño de políticas agrícolas ha dado lugar a la invención de nuevos instrumentos, haciendo más compleja su implantación.

\section{La Unión Europea}

A diferencia de Estados Unidos, en la Unión Europea el conjunto de las transferencias derivadas de programas de pagos gubernamentales no supera los montos que implican las medidas de sostén de precios. La PAC fue diseñada para basarse primordialmente en transferencias de los consumidores, al aislar de los precios internos de los del mercado mundial, y ese esquema aún no ha sido abandonado, según lo muestran los datos de la oCDE. Sin embargo, en el largo plazo, los primeros han mantenido una tendencia creciente mientras los segundos han disminuido. Desde 1997, las formas de apoyo distintas a las de sostén de precios habían estado descendiendo, pero esta tendencia se ha revertido en los dos últimos años de información disponible. Dicha tendencia ha sido observada en las medidas que abren una brecha entre los precios domésticos y los del mercado mundial. Es probable, por otra parte, que el comportamiento de los últimos años sea expresión, hasta cierto punto, de la apreciación del euro frente al dólar.

La Unión Europea adoptó un enfoque gradual de retiro de las medidas de sostén de precios de mercado, de acuerdo con la ruta definida en la reforma de la PAC de 1992. En tal sentido, la trayectoria de la estimación del apoyo mediante el sostén de precios de mercado muestra que la Unión Europea ha sido consistente en el largo plazo. Por otra parte, el desplazamiento hacia pagos muestra que también ha sido consistente en relación con el objetivo de hacer controlable el gasto de la PAC, pues tal tipo de transferencias no se ha disparado, más bien habían mantenido una tendencia decreciente. El comportamiento registrado en los últimos años, tanto del sostén de precios como de pagos, sugiere que la Unión Europea se ha sentido bastante cómoda al apoyar a sus productores, dadas las inconsistencias de Estados Unidos respecto de su compromiso con la reforma de las políticas agrícolas. Esto es, ha ganado márgenes de libertad.

Los montos globales de los pagos por hectárea o número de animales habían experimentado una inclinación al descenso desde 1997, pero han repuntado en el último año. A pesar de esa reacción, los pagos basados en la superficie y el número de animales tenderán a descender en los siguientes años, pues con la revisión de medio término de la Agenda 2000 se ha acordado una ruta de desplazamiento hacia pagos completamente desconectados, a fin de sacar de la negociación altos montos de apoyo hacia los productores. Por consiguiente, es de esperar que se incrementen los pagos por derechos históricos.

Desde 1992, el esquema de política de la Unión Europea se basa sustancialmente en dos categorías de política: soporte de precios de mercado (MPS) y pagos basados en el área o el número de animales. Adicionalmente, ha recurrido a pagos basados en: $a$ ) el uso de insumos, $b$ ) restricciones sobre el uso de insumos, $c$ ) la producción, y $d$ ) el ingreso agrí- 


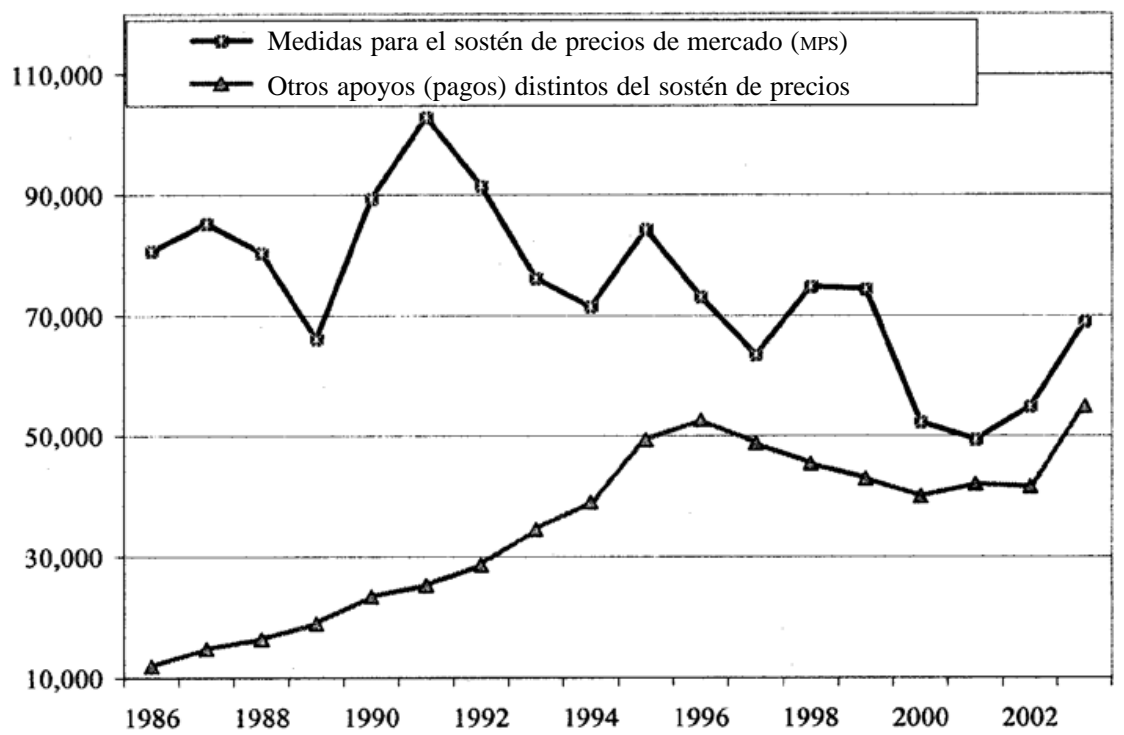

Gráfica 4. Unión Europea. Evolución comparativa de las medidas de sostén de precios de mercado (MPS) y el conjunto de las otras medidas de apoyo al productor, 1986-2003 (millones de dólares).

Fuente: http://oecd.org/document/58/0,2340,en_2649_33773_32264698_1_1_1_1,00.html

cola global. Los basados en derechos históricos, clasificados como los más desconectados, no han sido relevantes hasta el momento. En tal sentido, su desplazamiento hacia instrumentos desvinculados ha sido muy lento. Comparativamente, las políticas europeas no están desconectadas. El esfuerzo de reforma se ha centrado en el debilitamiento de los esquemas de sostén de precios, en tanto se garantiza el control del gasto, lo cual ha sido conseguido mediante los pagos basados en el área o el número de animales.

Discursivamente, la Unión Europea ha impulsado el condicionamiento de los apoyos a la toma de medidas medioambientales y de otro tipo, a las cuales la sociedad europea asigna alto valor. No obstante, los datos de la OCDE no muestran grandes cambios. Su insuficiente avance explica que se hayan tomado nuevos acuerdos para presionar su implantación, tanto en la Agenda 2000 como en la revisión de medio término de 2003. En este terreno, al parecer, la Unión Europea tiene un problema de coherencia con su propio discurso.

\section{México}

Según la base de datos de la OCDE, el grueso de los apoyos a los productores mexicanos ha sido provisto por el sostén de precios de mercado. En el periodo 2001-2003, 66.6\% de la estimación del apoyo al productor correspondía a sostén de precios y $33.4 \%$ a otras medidas de apoyo. En esa perspectiva, el esquema de política de México se alinea más al de la Unión Europea que al de Estados Unidos, aunque su disciplina ha sido mayor en lo que se

\section{Desaarrollo}




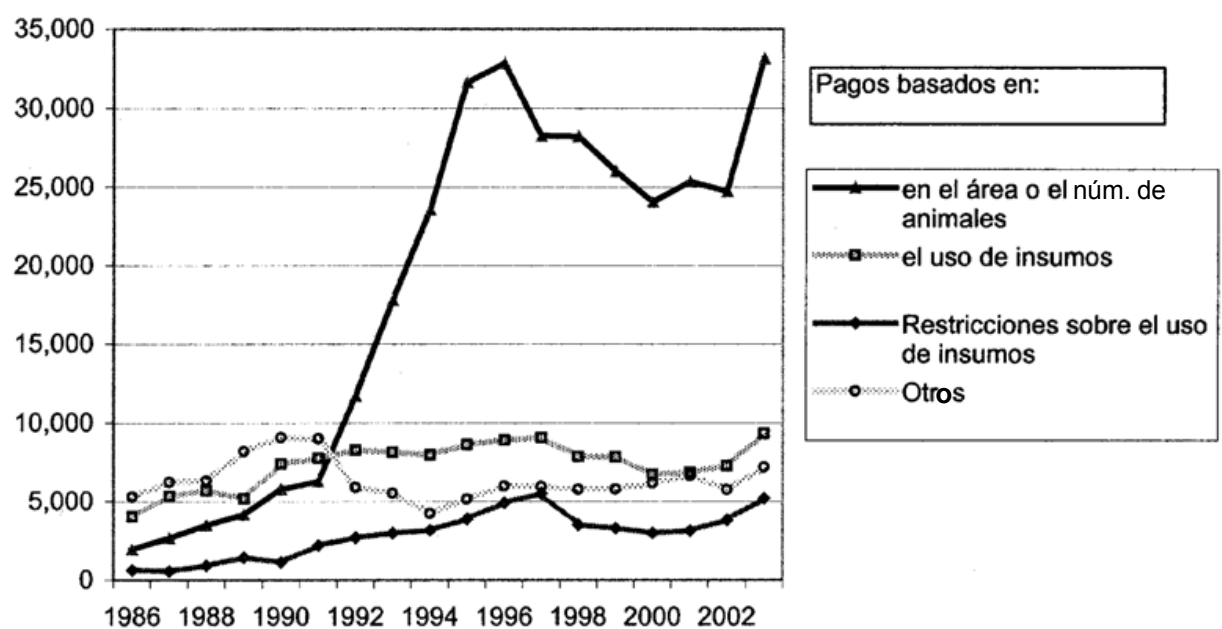

Gráfica 5. Unión Europea. Evolución e importancia de las distintas categorías consideradas para el cálculo de la estimación del apoyo al productor (PSE) distintos del sostén de precios de mercado (MPS), 19862003 (millones de dólares).

Fuente: http://oecd.org/document/58/0,2340,en_2649_33773_32264698_1_1_1_1,00.html

refiere al incremento de los apoyos basados en el gasto público. La disciplina en el gasto destinado al campo ha sido bastante rígida, según lo muestra la forma casi horizontal de la línea que agrupa las medidas de apoyo distintas del sostén de precios de mercado. Además, a partir de 1996, hay una inclinación a que se incremente el componente de apoyo por medio de precios.

Conforme a la base de datos de la OCDE, México no sólo no avanzó en la trayectoria definida hacia una mayor orientación de mercado, sino que retrocedió. El comportamiento antes descrito puede parecer extraño al analista de políticas agrícolas en México, dada la radicalidad habida en lo referente al abandono de precios de garantía, apertura externa y desmantelamiento de Compañía Nacional de Subsistencias Populares (CONASUPO) y otras empresas paraestatales relacionadas con la comercialización. En esas circunstancias, emerge una pregunta: ¿por qué a pesar de la profundidad de la reforma mexicana los datos de la OCDE sugieren que México descansa, en mayor medida que antes, en esquemas de apoyo al productor mediante una brecha entre precios domésticos y precios mundiales? Desde la perspectiva de este artículo, la respuesta está en los defectos de la metodología de la OCDE, que tiende a sobreestimar o subestimar el apoyo a los productores.

En el caso de México, los datos de la OCDE corresponden en su punto de arranque a un periodo de alta protección en las fronteras y de elevada inestabilidad económica. Esta última estuvo asociada a un proceso inflacionario, difícil de controlar, en un escenario de ajustes cambiarios recurrentes, en el cual la economía tenía necesidad de generar recursos externos para cubrir la deuda (Lustig, 1994). En tal sentido, el tipo de cambio dio 


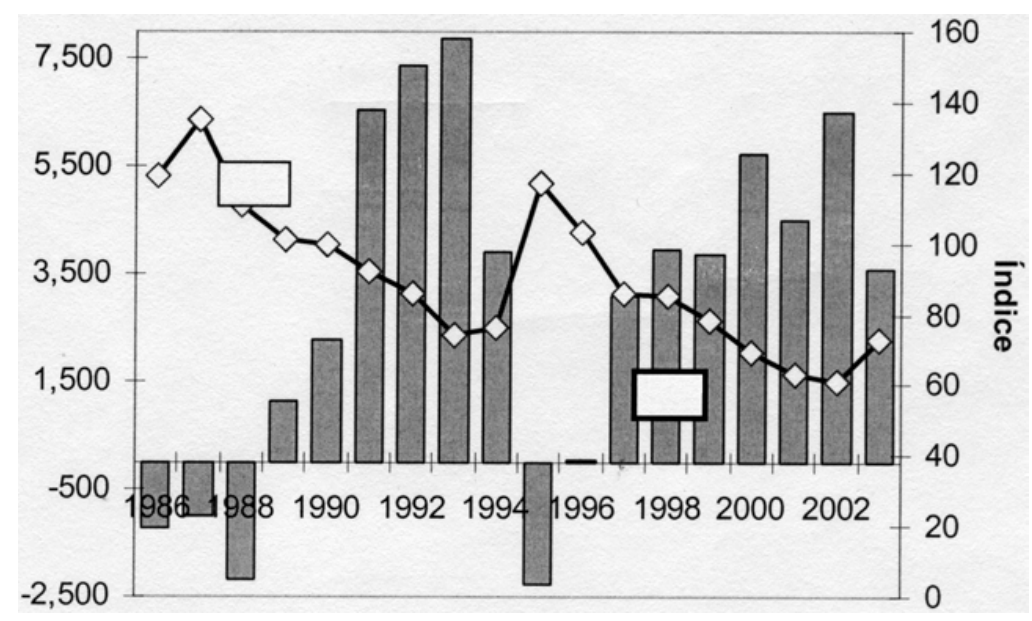

Gráfica 6. México. Evolución comparativa de la estimación del apoyo al productor mediante sostén de precios de mercado (MPS) y del índice de tipo de cambio real (ITCR), 1986-2003 (millones de dólares).

Fuente: http://oecd.org/document/58/0,2340,en_2649_33773_32264698_1_1_1_1,00.html; http://www.banxico.org.mx/sie/cuadros/CR60.html

competitividad a la producción interna, lo cual se vio reflejado en montos estimados de transferencias negativos o bajos. Sin embargo, la brecha de precios se amplió al estabilizarse la economía y convertirse al tipo de cambio en un instrumento de disciplina de precios.

En la Gráfica 6 se ilustra cómo el monto estimado para la MPs sigue un patrón inverso a la evolución del tipo de cambio real calculado por el Banco de México. Las transferencias a favor de los productores, derivadas de la brecha de precios, crecen cuando el tipo de cambio real tiende a caer (sobrevaluándose o apreciándose) y disminuyen hasta volverse negativas, incluso, cuando el tipo de cambio real sube (subvaluándose o depreciándose). Aunque el ajuste no es perfecto, dado que intervienen medidas de política que afectan el comercio, la relación entre ambos indicadores es muy estrecha. También puede observarse que regularmente el tipo de cambio ha tendido a mantenerse sobrevaluado a lo largo de los años.

La estimación MPs pretende medir las transferencias hacia los productores, las cuales se derivan de medidas de política que impiden la transmutación de los precios externos en domésticos..$^{10} \mathrm{~A}$ mayor brecha, mayor transferencia; sin embargo, cabe hacerse la pregunta de hasta dónde el cálculo es correcto, si ambos precios reflejan el efecto distorsionante del tipo de cambio. ¿Son correctos los precios que se derivan de la existencia de una

10 El problema de transmisión de precios no ha sido bien estudiado. Yúnez y Barceinas (2003), en un reciente análisis del sector agropecuario y el TLCAN, con base en una serie de 22 años, no encuentran un cambio estructural hacia el cierre de la brecha de precios, a pesar de los cambios en las políticas. Aunque los precios domésticos, en una gama de productos, tienden a seguir la evolución de los precios en Estados Unidos, ello ocurre con un retraso de 20 meses. No explican por qué. El retraso puede deberse a los efectos de políticas comerciales o de orden interno, pero también estar asociado a factores de estacionalidad y a la forma en que funcionan los mercados. 
subvaluación o sobrevaluación? En el caso de la segunda, los precios domésticos parecen ser más altos de lo que en realidad son, mientras que los externos parecen más bajos; por consiguiente, la respuesta a la pregunta no puede ser positiva. Por el contrario, a mayor grado de desviación del tipo de cambio respecto de 100 , menos correctos son esos precios. En conclusión, la sobrevaluación conduce a que la magnitud MPs, la cual pretende cuantificar las transferencias a los productores desde los consumidores mediante precios, esté sobreestimada y sea, por tanto, engañosa. Lo inverso ocurre en una situación de subvaluación.

El tipo de cambio está explicando por qué la variabilidad de los apoyos al productor por medio de MPs es tan acentuada en comparación con las medidas que descansan en pagos gubernamentales y, también, por qué este país parece haber retrocedido respecto de la situación de los primeros años considerados en la serie, cuando el marco de protección aún no era desmantelado. Es decir, por qué México parece estar descansando en medidas que distorsionan precios y ser más proteccionista actualmente que antes de la reforma.

Para comparaciones internacionales, la metodología de la OCDE no descuenta el efecto del tipo de cambio, asumiendo implícitamente que éste, como expresión de la macroeconomía, influye de igual manera en todos los sectores de actividad económica. Esto no es así, ya que tiene efectos diferenciados en los agentes económicos, sesgándose en contra de los productores cuando se está en una situación de sobrevaluación. En realidad, por este medio los productores hacen transferencias a los consumidores, dado que son obligados a vender a precios más bajos de los que se derivarían de una situación de equilibrio en el

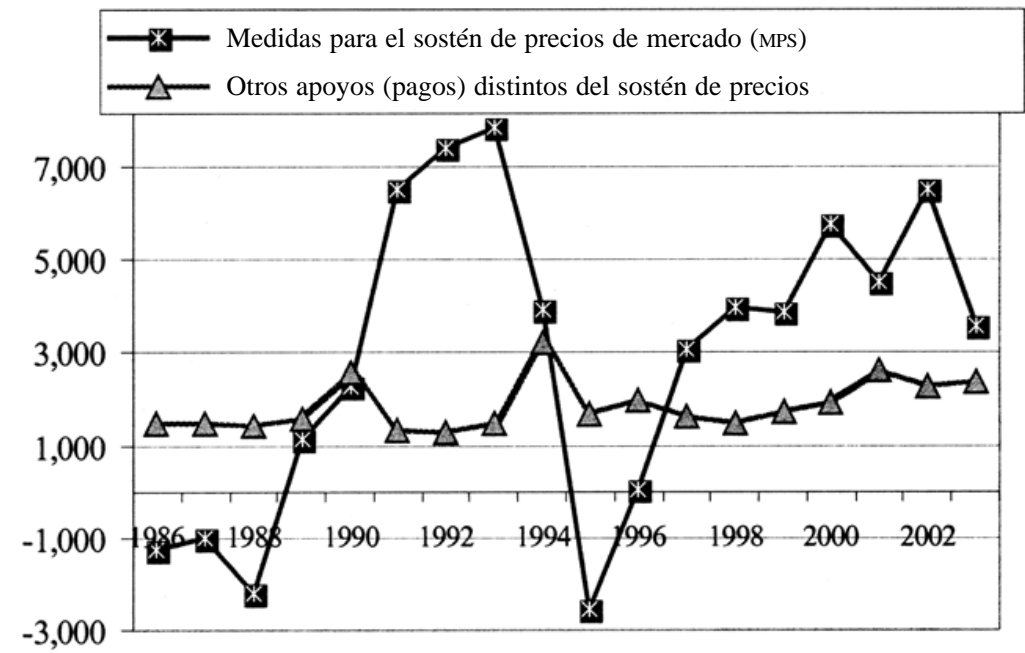

Gráfica 7. México. Evolución comparativa de las medidas de sostén de precios de mercado (MPS) y el conjunto de otras medidas de apoyo al productor, 1986-2003 (millones de dólares).

Fuente: http://oecd.org/document/58/0,2340,en_2649_33773_32264698_1_1_1_1,00.html 
tipo de cambio. Sin embargo, la metodología de la OCDE conduce a que la estimación de las transferencias de los consumidores aumente a mayor sobrevaluación del tipo de cambio, conduciendo a paradojas como la de México.

En lo que se refiere a pagos o transferencias gubernamentales a favor de los productores, el esquema mexicano de apoyos muestra menor grado de complejidad que los de Estados Unidos y la Unión Europea. De acuerdo con las categorías de clasificación de la OCDE, los apoyos se concentran básicamente en derechos históricos (PROCAMPO, sustancialmente), pagos basados en el uso de insumos y en la producción. Los demás conceptos son prácticamente irrelevantes. En promedio, en el lapso 2001-2003, los pagos basados en derechos históricos representaron 17\% de la PSE, mientras que los basados en el uso de insumos 9.2\%. En esas dos categorías, más el monto correspondiente a la MPs, se concentró $92.7 \%$ de la PSE.

El esquema de política de México había descansado preponderantemente en pagos basados en el uso de insumos, acorde con la terminología de la OCDE, pero este tipo de transferencias públicas ha caído por efecto de las reformas. En sentido inverso, su descenso ha sido paliado con la introducción de los basados en derechos históricos, los cuales se constituyeron en un componente nuevo en el esquema de política de México. No obstante, a partir de 1998, los pagos basados en el uso de insumos frenaron su descenso. Además, en los últimos años han ganado cierta importancia los pagos basados en la producción, mediante Apoyos y Servicios a la Comercialización Agropecuaria (ASERCA), por ejemplo, los cuales anteriormente eran casi inexistentes.

\section{La evolución del \%PSE}

De la estimación del apoyo al productor (PSE), la OCDE deriva su indicador más importante, la participación porcentual de las transferencias en el total de ingresos agrícolas brutos de los productores (\%PSE), el cual es definido como la razón entre el valor de los ingresos agrícolas brutos totales (incluyendo el apoyo mediante soporte de precios de mercado) y la producción, valorada en precios del mercado mundial (sin apoyo). El \%PSE, según la metodología de la OCDE, indica la participación de las transferencias en el valor total de los ingresos agrícolas brutos o, bien, los ingresos agrícolas brutos derivados de las políticas. En sentido inverso, dado el valor del \%PSE, la diferencia respecto de 100 indica cuánto de los ingresos agrícolas brutos se deriva del mercado, sin consideración de los apoyos.

Conforme a las estimaciones de la OCDE, en el periodo 2001-2003 el \%PSE ha sido de $21.2 \%$ en México, en promedio. Es decir, poco más de una quinta parte del ingreso de los productores provino de transferencias, en tanto el resto fue obtenido del mercado. Ese porcentaje era mucho más bajo anteriormente, habiéndose visto incrementado en los últimos años. Para la Unión Europea, en el periodo 2001-2003, el \%PSE fue de 35.5\%, en tanto que para Estados Unidos fue de 20\%. A diferencia de México, en ambos casos hay un

\section{Desaarrollo}




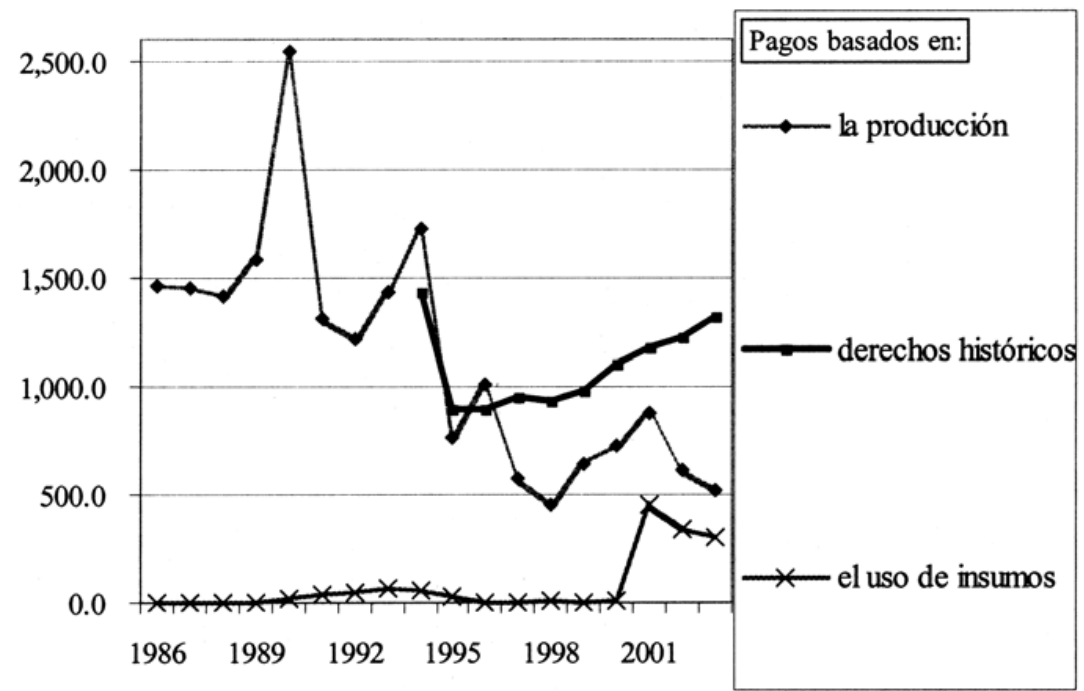

Gráfica 8. Evolución e importancia de las distintas categorías consideradas para el cálculo de la estimación del apoyo al productor (PSE) en México, distintas del sostén de precios de mercado (MPS).

Fuente:

http://oecd.org/document/58/0,2340,en_2649_33773_32264698_1_1_1_1,00.html

descenso en años recientes. Los datos indican que las transferencias son muy importantes para las potencias comerciales, más en el caso de la Unión Europea que en el de Estados Unidos. México habría tendido a acercarse a Estados Unidos, partiendo de más bajos $\%$ PSE. Sin embargo, debe tenerse presente que la sobreestimación de la medida MPS se reproduce en la PSE y, finalmente, en el \%PSE. La Gráfica 9 es suficientemente ilustrativa.

Los \%PSE sugieren que no ha habido grandes avances en las reformas, en ninguno de los tres casos. En promedio, el \%PSE era de 38.9\% de 1986 a 1988 en la Unión Europea, para caer a 35.5\% en 2001-2003. Al inicio de la reforma (1990-1993) ese porcentaje era de 39\%. También en Estados Unidos el nivel de los últimos tres años, en promedio, fue más bajo que el existente en el periodo 1986-1988, 20\% contra 25.3\%, pero es más alto que el porcentaje observado en los años 1995-1997, 12.9\%. Así pues, los productores estadounidenses descansan en la actualidad de forma más pesada en las transferencias, en comparación con la situación que se tenía al ser introducidas las reformas de 1996.

En el largo plazo, México pasó de una situación de 0\% de \%PSE, de 1986 a 1988, a 21.2\% en el periodo 2001-2003, en promedio. Ese porcentaje era de 8.4\% en 1988-1990, periodo correspondiente al de arranque, propiamente, de las reformas de las políticas agrícolas. Por tanto, conforme a estos datos, los productores mexicanos habrían incrementado notablemente su grado de dependencia de las transferencias. En tal sentido, simplemente no habría habido reforma alguna hacia una mayor orientación al mercado. A un resultado de este tipo conduce la metodología de la OCDE, al no considerar el efecto del tipo de cambio en la estimación de sus categorías. 


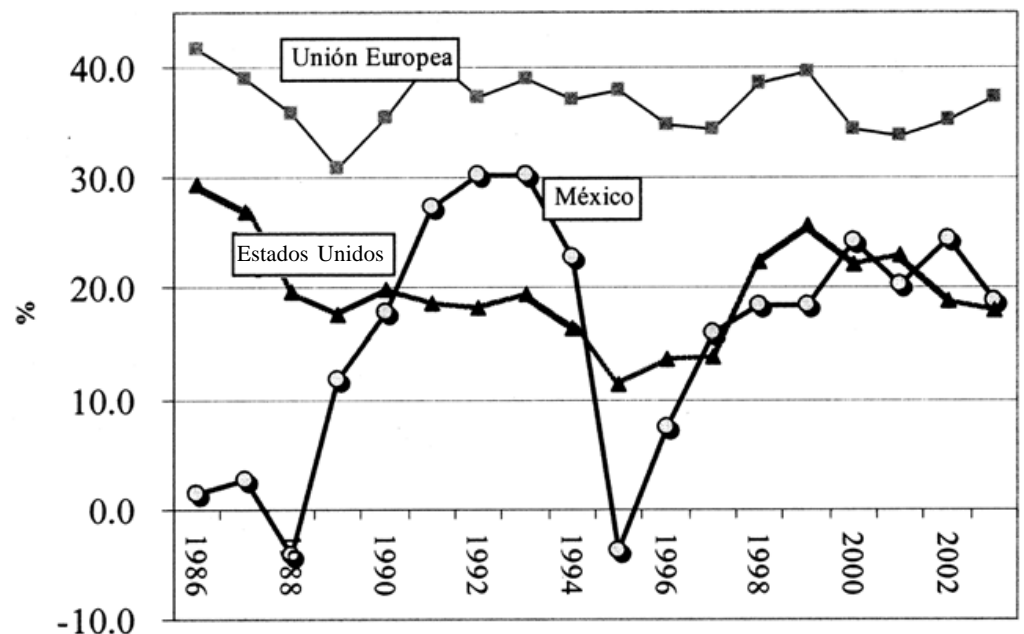

Gráfica 9. Evolución comparativa de la participación porcentual de las transferencias en el total de ingresos agrícolas brutos de los productores (\% PSE).

Fuente: http://oecd.org/document/58/0,2340,en_2649_33773_32264698_1_1_1_1,00.html

\section{Conclusiones}

Los datos de la OCDE muestran que las reformas de las políticas agrícolas han quedado por detrás de las expectativas. Esto es lo que muestra la estimación del apoyo al productor en los casos de las potencias agrícolas. Aunque haya ocurrido un desplazamiento hacia medidas distintas del sostén de precios de mercado, los gobiernos están ahí todavía, respaldando a sus productores. Este desplazamiento ha llevado a mayor diversidad de programas y complejidad en las políticas, pero no a su desaparición. Las únicas limitantes han sido la capacidad presupuestaria de los países y su habilidad para diseñar programas que escapen a las disciplinas de la omC y a la crítica de las políticas agrícolas.

Los niveles de apoyo, mediante precios o transferencias gubernamentales, continúan siendo más altos en la Unión Europea que en Estados Unidos, pero dicha asociación de países ha mostrado mayor consistencia en su planteamiento de reforma. Dado el liderazgo de Estados Unidos, ello suscita dudas en torno a las perspectivas del enfoque básico que determinó las reformas de los años noventa. Es probable que termine imponiéndose un cambio de apreciación. Las vicisitudes de la nueva ronda de negociaciones multilaterales —de Doha, denominada "del desarrollo" - parecen apuntar en ese sentido, ${ }^{11}$ así como la le-

11 Dada la extensión del artículo no es posible abordar aquí el débil compromiso inicial de Estados Unidos con el lanzamiento de la nueva ronda sobre comercio y la resistencia de ese país, así como de la Unión Europea, a hacer mayores concesiones a los países en desarrollo. Tampoco en torno a las diversas posiciones que se han expresado en la Ronda de Doha en distintos momentos. Para una explicación del fracaso inicial en su lanzamiento, véase Schoot (2000). Un perspectiva crítica respecto

\section{Desarrorollo}


gislación agrícola estadounidense de 2002. Sin embargo, ello dependerá de cuál sea la evolución de los precios de los productos agrícolas y de cómo reaccione el gobierno de Estados Unidos ante una coyuntura de tal tipo, a fin de defender el ingreso de sus productores y su posición en el comercio internacional.

Por otra parte, la información de la OCDE sugiere que México ha retrocedido en lo que se refiere a la orientación de mercado de sus políticas. Sin embargo, tal resultado no es consistente con la profundidad de los cambios realizados en esa dirección desde finales de los años ochenta. En este país, los precios de garantía desaparecieron, el Estado fue retirado del proceso de comercialización directa y del comercio agrícola, al ser desaparecida la paraestatal CONASUPO, y la protección en frontera descendió drásticamente - el arancel promedio ponderado para el sector agropecuario fue de $2.2 \%$ en el año 2003 (Fox, 2004)—. El proceso de apertura se acentuó a lo largo de los años, debido al TLCAN y a los numerosos acuerdos con distintos países y regiones, lo cual se ha visto reflejado en el crecimiento de las exportaciones y, sobre todo, de las importaciones.

La contradicción, según se ha señalado en este trabajo, se debe a los defectos de la metodología de la oCDE, pues el monto más importante de la estimación del apoyo al productor mexicano se deriva de las diferencias entre los precios domésticos y los mundiales usados como referencia, es decir, de la categoría MPs (véase Gráfica 7). Como para efectos de comparaciones internacionales no se descuenta el efecto del tipo de cambio sobre los precios, en un contexto de persistente sobrevaluación el apoyo tiende a sobreestimarse sistemáticamente, lo cual distorsiona la comprensión de los cambios reales en las políticas y sus efectos, así como el cálculo de los beneficios realmente percibidos por los productores. Al analizar el caso de México, el usuario de los indicadores de la oCDE debe tener clara esa distorsión.

Los apoyos gubernamentales (pagos) distintos del sostén de precios han funcionado en sentido compensatorio del descenso de la protección en frontera o como un mecanismo para la compra de las reformas, en todos los casos. En México, éstos han mostrado una inclinación al alza en los últimos años, al aumentar la importancia de la Cámara de Diputados en la asignación de presupuestos y ampliarse el espacio para el cabildeo de actores organizados. Sin embargo, no hay bases para afirmar que hayan sido efectivos en compensar el descenso de la protección en frontera y de la desaparición de otras medidas de intervención respecto de la formación de precios — que la metodología de la ocDE hace ver como si se hubieran incrementado, contradictoriamente- - Vistos en el largo plazo, la evolución de las transferencias gubernamentales ha sido muy estable, como reflejo del acento puesto en la disciplina fiscal y en la estabilidad macroeconómica.

de la posición de los países desarrollados se puede encontrar en los documentos de Oxfam International, véase en particular http://www.oxfam.org/esp/pdfs/bp150605_Una_Ronda_gratis.pdf. Además, en la página de la Organización Mundial de Comercio se puede seguir la dinámica de las negociaciones, véase en especial http://Www.wto.org/spanish/tratop_s/agric_s/negs_bkgrndoo_contents_s.htm. 


\section{Bibliografía}

FAO, FAOSTAT, FAO Statistical Data, http://apps.fao.org, 2004.

Folmer, C. et al., The Common Agricultural Policy Beyond the MacSharry Reform, Amsterdam, ELSEVIER, 1995.

Fox Q., V., Anexo. Cuarto informe de gobierno, México, Poder Ejecutivo Federal, 2004.

Gardner, B., European Agriculture. Policies, Production and Trade, Londres, Routledge, 1996.

Grant, W., The Common Agricultural Policy, Londres, Macmillan, 1997.

Haniotis, T. y P. Bascou, "The PSE: Is it Reflecting, or Distorting, the Trade Impact of Agricultural Policies?", en http://www.ecostat.unical.it/ 2003agtradeconf/Contributed\%20papers/ Haniotis\%20and\%20Bascou.pdf, 2003.

http://oecd.org/document/58/0,2340,en_2649_ 33773_32264698_1_1_1_1,00.html.

http://www.banxico.org.mx/sie/cuadros/CR60.html. http://www.oxfam.org/esp/pdfs/bp150605_Una_ Ronda_gratis.pdf.

http://www.wto.org/spanish/tratop_s/agric_s/ negs_bkgrnd00_contents_s.htm.

IATP, "United States Dumping on World Agricultural Markets", en http://www.tradeobservatory.org/ Library.cfm?filename $=U S \_D u m p i n g \_o n \_$ World_Agricultural_Markets_Febru.pdf,,2004.

Ingersent, K.A. y A.J. Rayner, Agricultural Policy in Western Europe and the United States, Londres, Edward Elgar, 1999.

Izam, M. y V. Onffroy de V., El sector agrícola en la integración económica regional: Experiencias comparadas de América Latina y la Unión Europea, Santiago de Chile, CEPAL, 2000.

Knutson, R.D., J.B. Penn y B.L. Flinchbaugh, Agricultural and Food Policy, 4a. ed., Upper Saddle River, Nueva Jersey, Prentice Hall, 1998.

Krueger, A.O., M. Schiff y A. Valdés, The Political Economy of Agricultural Pricing Policy, vol. 1, Washington, The World Bank, 1991.

Lustig, N., Hacia la reconstrucción de una economía, México, FCE, 1994.

Massot, M.A., "Los desafíos actuales de la política agrícola común, seminario", 30 de abril de 2002. UACH-DICEA, en amassot@europarl.eu.int.

McCalla, A.F., Agricultural Policies and Markets, Nueva York, Macmillan 1985.
Normile, M.A. y S.E. Leetmaa (coordinadores), U.S. EU Food and Agriculture Comparisons, Washington, USDA, 2004.

OECD, Agricultural Policy Reform: New Approaches, París, 1994.

- Examen de las politicas agrícolas de México, París, 1997.

-, Agricultural Policies in OECD Countries. Monitoring and Evaluation, París, 2000.

, Producer and Consumer Support Estimates. OECD Database. User's guide, París, 2001a.

- Multifunctionality. Toward an Analytical Framework, París, 2001b.

- Multifunctionality. The Policy Implications, París, 2003.

_ , "Producer and Consumer Support Estimates, OECD Database 1986-2003", en http://www.oecd. org/dataoecd/33/50/32361372.ZIP, 2004.

Orden, D., R. Paarlberg y T. Roe, Policy Reform in American Agriculture, Chicago, The University of Chicago Press, 1999.

Paarlberg, P.L., M. Bredhal y J.G. Lee, "Multifunctionality and Agricultural Trade Negotiations", en Review of Agricultural Economics, núm. 24, 2002, pp. 322-335.

Piccinini, A. y M. Loseby, Agricultural Policies in Europe and the USA. Farmers Between Subsidies and Market, Palgrave, Basingstoke, Hampshire, 2001.

Ray, D.E., D.G. de la Torre U. y K.J. Tiller, Rethinking US agricultural policy: Changing course to secure farmer livelihoods Worldwide. Agricultural Policy Analysis Center, Knoxville, The University of Tennessee, 2003.

SARH, PROCAMPO, Vamos al grano para progresar, México, $\mathrm{s} / \mathrm{f}$.

Schoot, J.J., The wTO after Seattle, Washington, Institute for International Economics, 2000.

Wise, T.A., "The Paradox of Agricultural Aubsidies: Measurement Issues, Agricultural Dumping, and Policy Reform", en http://ase.tufts.edu/gdae/ Pubs/wp/04-02AgSubsidies.pdf, 2004

Yúnez, N.A. y F. Barceinas, "El TLCAN y la agricultura mexicana. XIX Seminario de Economía Mexicana", IIEC-UNAM, en $h t t p: / / w w w$.procesam.colmex. $m x$.

\section{Desarrrollo}

